\title{
APLIKASI METODE JOIN INVERSI SEISMIC GRAVITY UNTUK IMAGING BAWAH PERMUKAAN DAERAH GEOLOGI KOMPLEKS
}

\author{
Triswan Mardani Ade Surya ${ }^{1)}$, Widya Utama ${ }^{1)}$, Firman Syaifuddin ${ }^{1)}$, Lita Novitasari ${ }^{2)}$ \\ 1)Jurusan Teknik Geofisika, FTSP Institut Teknologi Sepuluh Nopember, ${ }^{2)}$ Jaya Enegry Buana \\ e-mail:Triswan5@gmail.com
}

\begin{abstract}
Abstrak. Kondisi geologi kompleks dekat permukaan terjadi ketika body batuan dengan kecepata tinggi terbawa dekat ke permukaan. Batuan tersebut dapat berupa batuan beku ataupun karbonat. Keberadaan batuan tersebut dapat menyebabkan meningkatnya kontras kecepatan dekat permukaan. Tingginya kontras kecepatan menyebabkan kesulitan untuk mendapatkan gambaran bawah permukaan dengan metode konvensional seperti travel time tomography. Join inversi dari dua data geofisika merupakan salah satu teknik untuk mendapatkan gambaran bawah permukaan. Pada studi ini metode yang digunakan adalah metode join inversi seismik dan gravity. Pada studi ini data yang digunakan adalah data seismik sintetik yang merupakan hasil dari forward modelling model kecepatan. Nilai kecepatan pada model memiliki rentang $1000 \mathrm{~m} / \mathrm{s}$ hingga $5800 \mathrm{~m} / \mathrm{s}$. Metode yang digunakan untuk forward modelling data seismik dan gravity adalah metode finite difference sedangkan metode talwani. Berdasarkan hasil penelitian didapatkan bahwa model kecepatan hasil join inversi tomografi travel time dan gravity lebih baik dibandingkan dengan metode travel time tomografi sendiri. Perbedaan yang signifikan ditunjukkan oleh bentuk dari bentuk body kecepatan tinggi dan munculnya lapisan dengan kecepatan rendah. Selain itu metode join inversi juga menunjukkan peningkatan gambaran struktur geologi, dan nilai kecepatan.
\end{abstract}

Kata Kunci: tomografi seismik waktu tempuh; join inversi seismik-gravity; pemodelan bawah permukaan

\begin{abstract}
Near surface geology complex condition is occur when high velocity bodies brought close to the surface. This body could be high velocity carbonates or igneous rocks. The presence of the bodies could cause high contras velocity change at near surface. This problem is difficult to solve using conventional velocity reconstruction technique such as travel time tomography. Join inversion of two geophysical data is one of many subsurface imaging technique. In this study we using joint seismic travel time tomography and gravity data to get near surface velocity model. This study we using synthetic seismic and gravity data, which result by forward modelling based on velocity model. Velocity value of the model range from $1000 \mathrm{~m} / \mathrm{s}$ to $5800 \mathrm{~m} / \mathrm{s}$. Then Forward modelling seismic and gravity data is done by data using finite difference method and Talwani method. To get subsurface model we using joint seismic gravity and first arrifal refraction travel time tomography. The result of this study show joint seismic travel time and gravity is better than travel time tomography. The difference is show on the shape high velocity body, and the appearance of low velocity layer which isn't show on travel time tomography velocity model. Joint inversion is show improve velocity biases and image of geological structure.
\end{abstract}

Keywords: seismic travel time tomography; joint inversion seismic-gravity; subsurface imaging

\section{PENDAHULUAN}

Geologi Kompleks adalah suatu kondisi dimana teknik imaging bawah permukaan konvensional tidak mampu bekerja secara maximum. Kondisi geologi kompleks terjadi ketika terjadi apabila perubahan kecepatan secara ekstrem baik secara horizontal maupun vertikal. Perubahan kecepatan yang ekstrem dapat diakibatkan oleh adanya body batuan yang memiliki kecepatan tinggi terbawa dekat permukaan contohnya adalah batuan beku dan karbonat. Selain itu perubahan kecepatan dapat diakibatkan lapisan low velocity anomaly yang berupa sedimen batubara. Keberadaan anomaly tersebut hanya bersifat lokal. Umumnya first arrival travel time tomografi mampu memberikan gambaran dekat permukaan secara akurat. Akan tetapi pada kasus geologi kompleks, metode tersebut tidak mampu memberikan gambaran bawah permukaan secara akurat. Sehingga diperlukan data pendukung yang sensitif 
terhadap keberadaan lokal anomaly seperti metode gravity.

Join inversi seismik travel time dan gravity merupakan salah satu metode tomografi yang dapat digunakan untuk mendapatkan gambaran dekat permukaan. Metode Join inversi seismik travel time dan gravity adalah gabungan dari dua metode tomography yaitu first arrival travel time tomography dan gravity inversion. Penggabungan kedua metode tersebut memanfaatkan teknik simultaneous joint inversion yang dimana pada prosess inversi, kedua metode tersebut saling mengkoreksi satu sama lain untuk menghasilkan model yang memiliki error terkecil. Keuntungan aplikasi metode JSGI adalah mampu memberikan gambaran lapisan yang memiliki kecepatan tinggi ataupun rendah yang berada dekat permukaan. Selain itu model kecepatan yang dihasilkan oleh metode JSGI dapat dijadikan dasar penentuan datum dan kecepatan lapisan lapuk untuk melakukan koreksi statik pada pengolahan data seismik refleksi.

\section{TINJAUAN PUSTAKA}

\section{Joint Inversi Seismic Gravity}

Algoritma joint inversi seismic gravity dapat menggabungkan informasi apriori ke dalam fungsi objectif model dengan menggunakan satu atau lebih fungsi pembobotan. Formula joint seismigravity inversion merupakan permasalahan constrained least square yang diselesaikan menggunakan pengali Lagrange dan iterative conjugate gradient untuk meminimalisir fungsi objektif yang berbentuk:

$$
\begin{aligned}
\phi_{t}(m)=\phi_{m}( & m)+\frac{1}{\lambda_{1}}\left[\phi_{d}+\phi_{d}^{*}\right] \\
& +\frac{1}{\lambda_{2}} \phi_{b}(m)+\frac{1}{\lambda_{3}} \phi_{x}(m) \\
& +\frac{1}{\lambda_{4}} \phi_{r p}(m)
\end{aligned}
$$

dengan: $\lambda_{i}, I=1, . .4$ adalah pengali Lagrange yang berbeda.
Fungsi regularisasi model $\phi_{m}(m)$ adalah:

$$
\begin{array}{r}
\phi_{m}(m)=\left(m-m_{0}\right)^{T} W_{m}^{T} W_{m}\left(m-m_{0}\right) \\
=\left\|W_{m}\left(m-m_{0}\right)\right\|_{L_{2}}^{2}
\end{array}
$$

dengan:

$\mathrm{m}$ dan $m_{0}$ masing-masing adalah model yang tidak diketahui dan model input.

$W_{m}$ adalah matrix pembobotan model yang termasuk di dalamnya fungsi pembobotan ketergantungan spasial, fungsi pembobotan tehadap kedalaman, operator smoothing dan informasi sebelumnya pada model.

Misfit data didefiniskan sebagai:

$$
\begin{aligned}
\phi_{d}(m)=(J m & \left.-d_{o b s}\right)^{T} W_{d}^{T} W_{d}(j m \\
& \left.-d_{o b s}\right) \\
& =\left\|W_{d}\left(J m-d_{o b s}\right)\right\|_{L_{2}}^{2}
\end{aligned}
$$

dengan:

$d_{o b s}$ adalah vector dari data pengukuran (yang di dalamya Nttravel time dan Ng obsevasi gravity);

$\mathrm{J}$ adalah matrix jacobian atau sensitivitas;

Wd adalah matrix pembobotan data yang memperhitungkan hubungan relative dari data hasil pengukuran dan efek noise pada data.

Sebuah penghalang logaritma (Li dan Oldenburg, 2003) didefiniskan sebagai:

$$
\begin{aligned}
\phi_{b}(m)=-\sum_{i=1}^{M} & {\left[\ln \left(\frac{m_{i}-m_{L i}}{m_{H i}-m_{L i}}\right)\right.} \\
+ & \left.\ln \left(\frac{m_{H i}-m_{i}}{m_{H i}-m_{L i}}\right)\right]
\end{aligned}
$$

dengan:

$\mathrm{H}$ adalah atas dan $\mathrm{L}$ adalah bawah; apabila $m_{i} \rightarrow m_{L i}$ atau $m_{i} \rightarrow m_{H i}$, sehingga $\phi_{b} \rightarrow$ inf.

$\mathrm{M}$ adalah jarak cardinal model dan sesuai dengan $\mathrm{Ms}+\mathrm{M} \rho$ yang masing-masing adalah prameter slowness dan densitas. $\phi_{x}(m)$ dan $\phi_{r p}(m)$ merupakan cross gradient dan hubungan fisika batuan. 
Cross gradient model didefinisikan sebagai:

$$
\phi_{x}(m)=\sum_{k=1}^{K}\left\|x_{k}\right\|_{L_{2}}^{2}
$$

dengan $\mathrm{K}$ merupakan grid nomor kolom. $x_{k}$ adalah cross matrix cross gradient dari densitas dan slowness.

$x_{k}$ di definisikan sebagai berikut:

$$
x_{k}=\nabla s_{k} x \nabla \rho_{k}=\left|\begin{array}{ccc}
i & j & k \\
\frac{\partial s_{k}}{\partial x} & \frac{\partial s_{k}}{\partial y} & \frac{\partial s_{k}}{\partial z} \\
\frac{\partial \rho_{k}}{\partial x} & \frac{\partial \rho_{k}}{\partial y} & \frac{\partial \rho_{k}}{\partial z}
\end{array}\right|
$$

dengan I, j, k adalah satuan sumbu koordinat kartesian vector. Kesamaan structural antara model slowness dan densitas didapatkan ketika $\nabla s_{k}$ dan $\nabla \rho_{k}$ berbagi posisi yang sama dan $x_{k}=0$. Hubungan fisik dari domain geofisika yang berbeda dapat diturunkan melalui hubungan fisika batuan.

Hubungan tersebut dinyatakan sebagai persamaan:

$$
\phi_{r p}(m)=\sum_{k=1}^{K}\left\|\rho_{k}-f_{r p}\left(s_{k}\right)\right\|_{L_{2}}^{2}
$$

Metode yang diusulkan di sini adalah join inversi simultan yang dapat diperluas ke beberapa domain dan sifat yang berbeda (misalnya, seismic-EMgravitasi) (Colombo, 2013).

\section{METODOLOGI}

Penelitian ini dilakukan dengan menggunakan data sintetik seismik dan gravity. Data seismik di modelkan dengan menggunakan metode Talwani sedangkan metode seismik dimodelkan dengan metode finite element. Model kecepatan yang digunakan untuk pemodelan data gravity dan seismik adalah sebagai berikut:

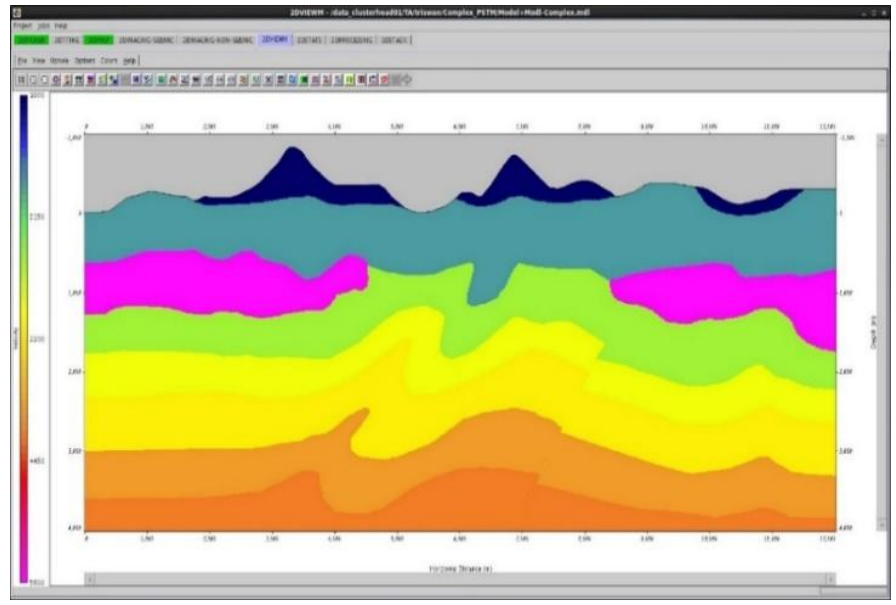

Gambar 1. Model Kecepatan Geologi Kompleks.

Data yang dihasilkan kemudian diolah dengan diagram alir pada Gambar 2 di halaman akhir, untuk mendapatkan model hasil inversi joint inversi seismic gravity. Metode Inversi Joint inversi seismi gravity menggunakan model pada Gambar 4 dan 5 yang dihasilkan dari travel time tomografi dan gravity inversi yang terlebih dahulu dilakukan masing-masing. Inversi travel time menggunakan model pada Gambar 3 yang dihasilkan dari plot first break pada kurva hubungan $\mathrm{t}-\mathrm{x}$ (waktu dan offset). Data first break didapatkan dari picking event yang pertama kali terekam pada data seismik.

\section{HASIL DAN PEMBAHASAN}

Gambar 3 (a) dan (b) adalah model kecepatan travel time tomografi dengan RMS misfit sebesar $86.3 \mathrm{~ms}$ dan $6.7 \mathrm{~ms}$. Travel time tomografi dilakukan sebanyak lima kali dengan tujuan untuk mendapatkan model yang memiliki RMS misfit terkecil sebelum dijadikan input pada inversi gravity.

Perbedaan yang signifikan antara kedua model kecepatan di atas khususnya pada resolusi model. Model 3(a) menggunakan grid dengan ukuran $65 \times 13 \mathrm{~m}$ dengan tujuan mendapatkan gambaran kasar anomali kecepatan rendah dan tinggi pada model. Selain itu, perbedaan yang terlihat dari gambar 3(a) dan (b) yaitu bentuk anomali kecepatan yang relatif kecil pada sisi kiri serta nilai kecepatan yang lebih besar pada body anomali sisi 
kanan dari $3400 \mathrm{~m} / \mathrm{s}$ pada tomografi ke-1 menjadi 4200 pada tomografi ke 5 .

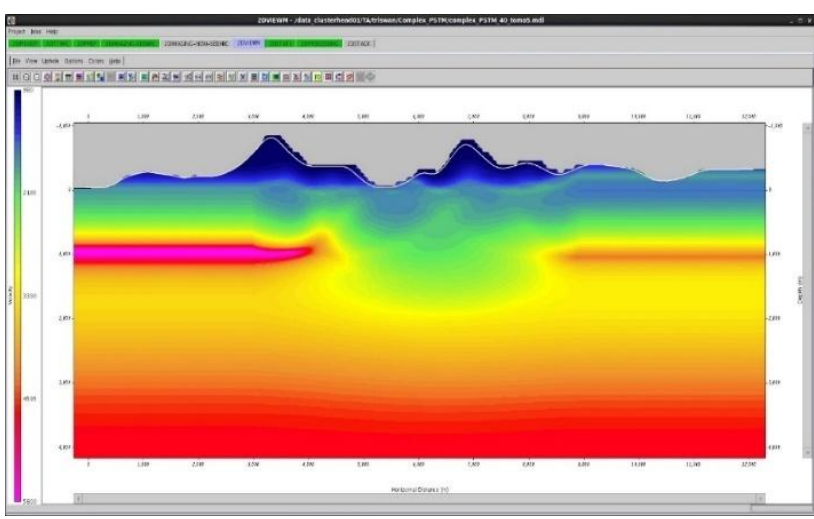

(a)

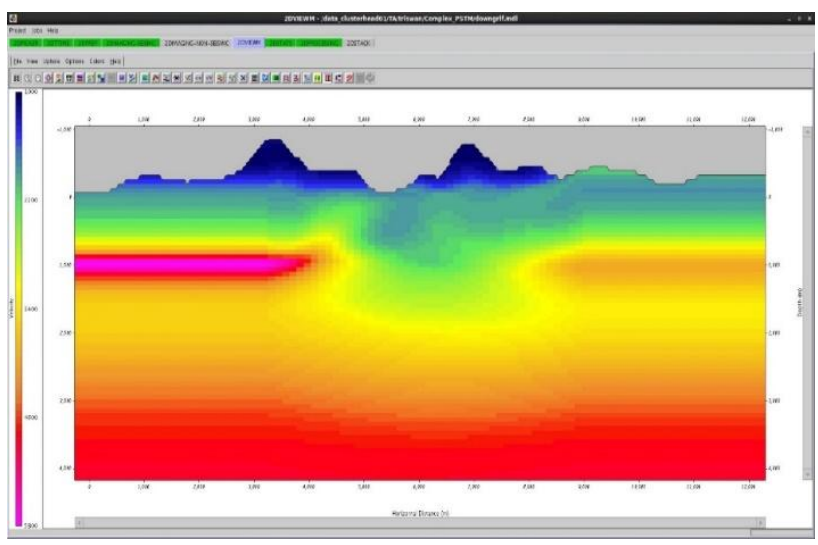

(b)

Gambar 3. Model Kecepatan Travel Time Tomography (a) Ke-1 dan (b) Ke-5.

Dari lima tomografi yang telah dilakukan, tidak didapatkan satu model mampu mendapatkan perlapisan di bawah batuan beku. Karena keterbatasan metode ray tracing yang digunakan hanya memperhitungkan sinar tercepat berdasarkan prinsip Fermat. Akibatnya, sinar yang datang belakangan berasal dari refraksi lapisan dibawah batuan beku tidak diperhitungkan pada proses rekonsruksi kecepatan. Selain itu adanya batuan beku dengan keceptan tinggi dekat permukaan menghambat sinar refraksi atau refleksi dari lapisan di bawahnya. Akibatnya sinar tersebut terperangkap di antara lapisan bawah body batuan kecepatan tinggi akibat kontras impedance sangat yang besar.

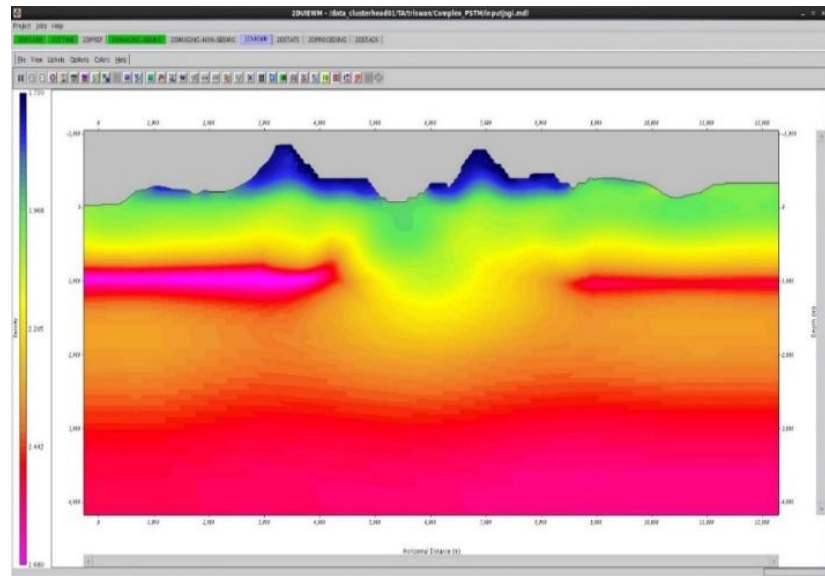

Gambar 4. Model Densitas Hasil Inversi Gravity.

Model kecepatan pada Gambar 3 (b) kemudian dikonversi menjadi model density dan dijadikan input inversi gravity. Parameter smoothing control sebesar yang digunakan sebesar 1. Gambar 4 adalah model densitas yang dihasilkan dari inversi gravity memperlihatkan ukuran body kecepatan tinggi lebih tebal dibandingkan oleh model hasil travel time tomography. Pada model densitas juga tidak terlihat lapisan dengan kecepatan rendah dekat permukaan. Model tersebut kemudian dijadikan input join inversi beserta model kecepatan pada Gambar 3(b).

Model kecepatan Gambar 5(a) yang dihasilkan dari Joint inversi seismic-gravity jika dibandingkan dengan travel tomografi (Gambar 3(a)) terlihat perbedaan yang signifikan yaitu munculnya anomali dengan kecepatan rendah yang berada seperti pada Gambar 1 dengan 980 m/s. Nilai tersebut lebih rendah $20 \mathrm{~m} / \mathrm{s}$ jika dibandingkan model sebenarnya. Peningkatan nilai kecepatan untuk body anomali kecepatan tinggi kiri sebesar 5600 $\mathrm{m} / \mathrm{s}$. Selain itu, bentuk sisi atas dari body memiliki kemiripan dengan body pada Gambar 1 khususnya pada dippingnya. Pada body kecepatan tinggi sebelah kiri nilai yang didapatkan sebesar 5000 $\mathrm{m} / \mathrm{s}, 600 \mathrm{~m} / \mathrm{s}$ di bawah nilai sebenarnya. Bentuk body sebelah kiri yang dihasilkan lebih sesuai dengan model sebenarnya jika dibandingkan dengan model hasil travel time tomography. Walaupun telah digunakan metode Joint inversi lapisan di bawah batuan beku tidak dapat terlihat. 
hal tersebut diakibatkan oleh kerena ketidak mampuan ray seismic untuk melewati batuan dengan kecepatan tinggi dekat permukaan sama halnya pada metode tomografi travel time.

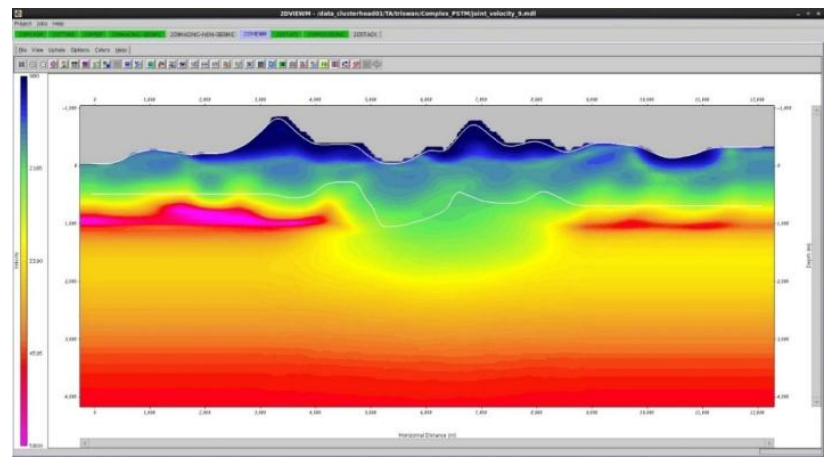

(a)

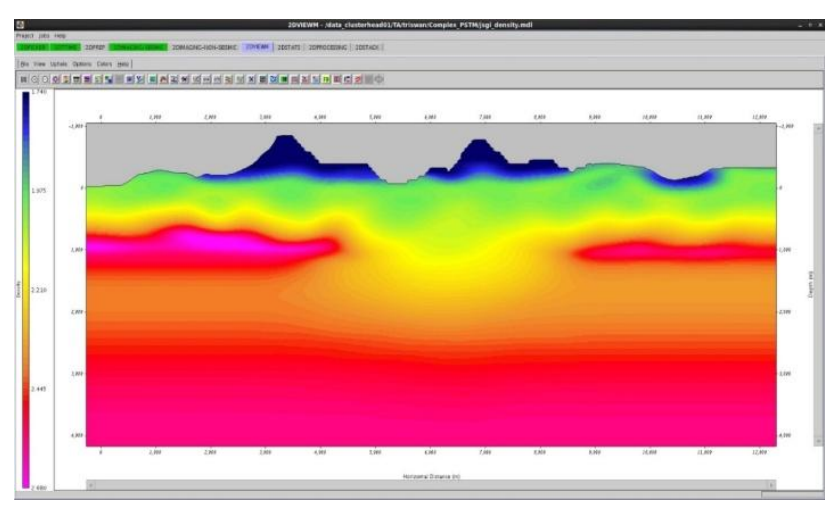

(b)

Gambar 5 (a) Model Kecepatan dan (b) Model Densitas Hasil Join Inversi Seismik-Gravity.

\section{PENUTUP}

\section{Kesimpulan}

Kesimpulan yang didapat dari penelitian ini antara lain.

1. Join seismik travel time tomografi mampu memberikan model bawah permukaan yang lebih akurat dibandingkan dengan metode travel time tomografi. Hal tersebut terbukti pada kasus model sederhana dan kasus model complex PSTM dimana JSGI mampu memberikan nilai kecepatan yang benar pada lapisan kecepatan tinggi dan memunculkan anomali dengan kecepatan rendah.

2. JSGI dan travel time tidak mampu melakukan imaging di bawah batuan yang memiliki kecepatan tinggi dekat permukaan karena gelombang seismik tidak mampu melewati batuan tersebut sehingga tidak ada informasi refleksi ataupun refraksi untuk lapisan yang berada di bawah batuan tersebut.

\section{Saran}

Saran yang dapat diberikan berdasarkan hasil dan kesimpulan untuk membangun hipotesahipotesa selanjutnya antara lain.

1. Pada kasus model serayu sebaiknya digunakan metode tomografi yang lebih advance yaitu reflection tomografi ataupun waveform inversion untuk mendapatkan perlapisan di bawah batuan beku.

2. Perlu dilakukan penelitian dengan metode geofisika yang lainnya seperti GPR atau geolistrik sebagai pembanding hasil posisi dan letak dari rekahan dan patahan.

\section{Ucapan Terima Kasih}

Penulis mengucapkan terima kasih kepada Pak Widya Utama dan Pak Firman Syaifuddin atas bimbingannya. Selain itu, penulis berterimakasih kepada Pak Nugraha sebagai direktur PT Jaya Energi Buana atas kesempatan mengerjakan tugas akhir di perusahaan beliu. Penulis juga tidak lupa berterima kasih kepada Ibu Lita Novitasari dan Bapak Heri atas bimbingannya selama di PT Jaya Energy Buana.

\section{DAFTAR PUSTAKA}

D. Colombo, D. R., 2013. 3D Seismic-gravity Simultaneous Joint Inversion. 75th EAGE Conference \& Exhibition Incorporating SPE EUROPEC. London, UK: EAGE.

Colombo, D., Rovetta, D. C., Sandova, Ley, R., Wang, W., \& Liang, C., 201). 3D Seismic-Gravity Simultaneous Joint Inversion for Near Surface Velocity Imaging. 75th EAGE Conference \& Exhebition.

Dengguo Zhou, D. R., 2014. 3D Joint Inversion of Seismic Traveltime and Gravity Data: A Case Study. SEG Annual Meeting. Denver: SEG.

Jie Zhang, M. N., 1998. Non Linear Refraction Travel Time Tomography. GEOPHYSICS, 1726-1737

Moser, T., 199). Shortest Ray Calculation of Seismic Ray. Geophysics, 59-67. 


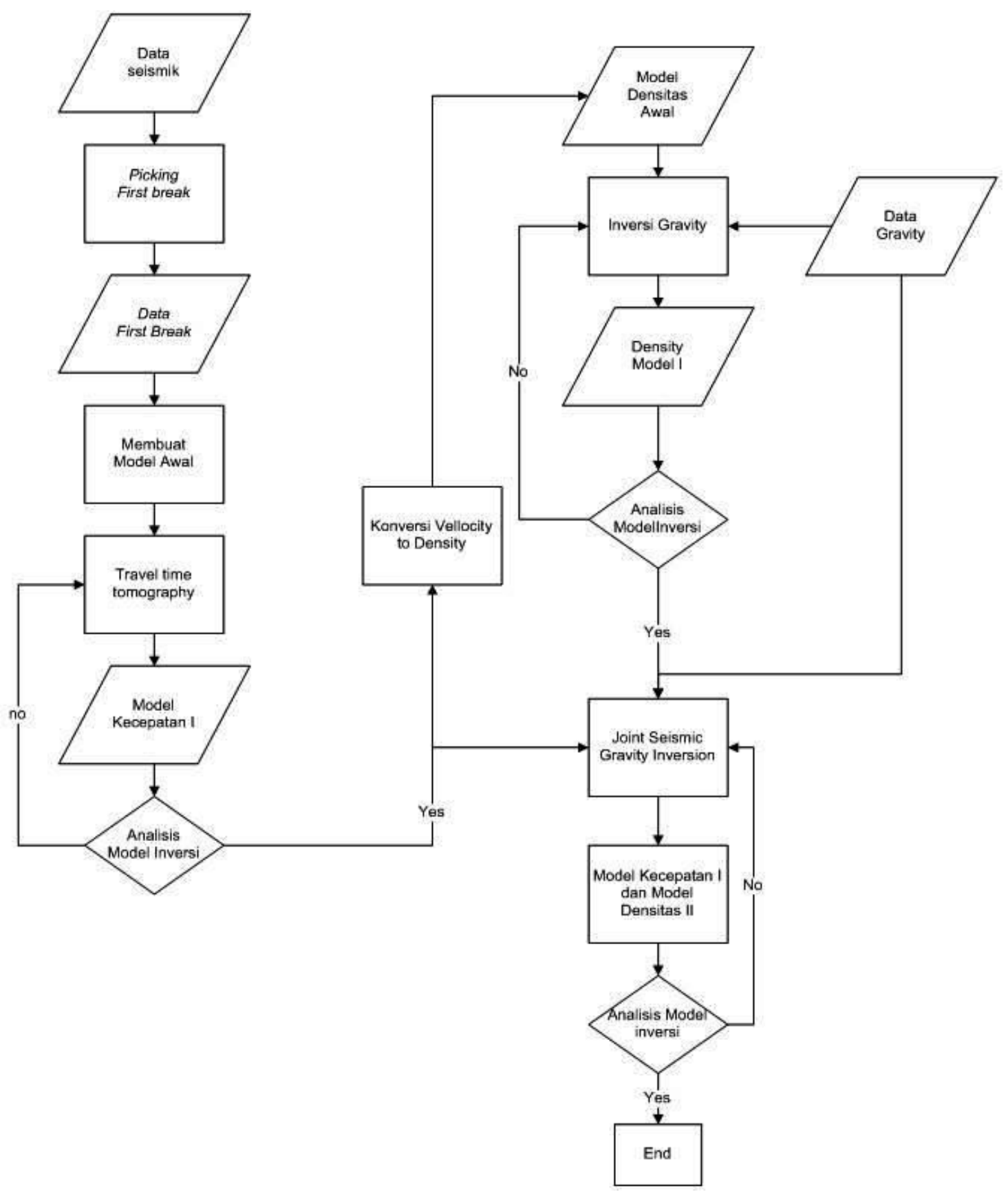

Gambar 2. Diagram Alir Joint Seismic Gravity. 